\title{
Is It More Effective to Prescribe a Proton Pump Inhibitor Separately before a Meal for the Eradication of Helicobacter pylori?
}

\author{
Gyu Won Lee, Jae Hyun Kim, Won Moon, Seun Ja Park, Moo In Park, Sung Eun Kim, Hye Jung Kwon, Youn Jung Choi \\ Department of Internal Medicine, Kosin University College of Medicine, Busan, Korea
}

\begin{abstract}
Background/Aims: The current standard regimen for the treatment of Helicobacter pylori infection is a combination of a proton pump inhibitor (PPI), amoxicillin, and clarithromycin. The aim of this study was to determine the effectiveness of PPIs taken separately before a meal for the treatment of $H$. pylori infection.

Materials and Methods: This retrospective study included 160 patients who were tested positive for rapid urease in Kosin Unversity Gospel Hospital between January 2008 and December 2012. The patients were divided into two groups ( $\mathrm{n}=80$ in each group) based on the method of administration of the $\mathrm{H}$. pylori triple therapy. Group A took a PPI before a meal and amoxicillin and clarithromycin after a meal. Group B took all three medications together after a meal. The ${ }^{13} \mathrm{C}$-urea breath test was performed after 4 weeks to assess the eradication of $H$. pylori.

Results: $H$. pylori was eradicated in 58/80 (72.5\%) patients in group A and 60/80 (75.0\%) patients in group B, with no significant difference between the groups $(P=0.719)$. Adverse effects occurred in 4 patients of group $\mathrm{A}$ and 7 patients of group $\mathrm{B}(5.0 \%$ and $8.8 \%$, respectively); however, the difference between the groups was not significant $(P=0.232)$.

Conclusions: Administration of all medicines at once after a meal may be the better prescription for treatment, considering patient convenience and improved likelihood of compliance. (Korean J Helicobacter Up Gastrointest Res 2018;18:110-114)
\end{abstract}

Key Words: Helicobacter pylori; Prescriptions; Proton pump inhibitors

\section{INTRODUCTION}

Helicobacter pylori, which was first identified in 1982 by Australian scientists Barry Marshall and Robin Warren, is a Gram-negative microaerophilic bacterium found in the stomach. ${ }^{1}$ It is known to cause chronic gastritis, peptic ulcers, mucosa-associated lymphoid tissue lymphoma, and stomach cancer. ${ }^{2}$ In a systemic review reported in Japan, Ito et al. ${ }^{3}$ found that $H$. pylori eradication therapy diminished the prevalence of gastric cancer by approximately one-third. Prospective studies have also reported that in the 10 years after $H$. pylori eradication, gastric atrophy and intestinal metaplasia significantly decreased, and these results may be associated with a reduction in gastric cancer occurrence. ${ }^{4,5}$ In 1997, the European Helicobacter Study Group recommended triple therapy as first-line treatment for $H$. pylori infection, which consists

Received: December 21, 2017 Revised: January 30, 2018 Accepted: February 27, 2018 Corresponding author: Won Moon

Department of Internal Medicine, Kosin University College of Medicine, 262 Gamcheon-ro, Seo-gu, Busan 49267, Korea

Tel: +82-51-990-5061, Fax: +82-51-990-5055, E-mail: moonone70@hanmail.net (1) ORCID: https://orcid.org/0000-0002-3963-8680 of a proton pump inhibitor (PPI), amoxicillin, and clarithromycin. Triple therapy has remained the first-choice regimen for the past decade and has been recommended by most consensus meetings, and by both European and American scientific societies. ${ }^{6}$

A gastric $\mathrm{pH}$ of 5.0 or greater should be maintained for effective eradication of $H$. pylori ${ }^{7}$ and the administration of PPI more than two times the usual dose is necessary to do that. ${ }^{8,9}$ PPIs increase the gastric $\mathrm{pH}$, which then decreases the loss of antibiotics through the gastric mucosa. This agent also improves the minimal inhibitory concentration of antibiotics, which leads to improved effects in the eradication of $H$. pylori. ${ }^{7,10,11}$ PPIs are most effective when the medicine is ingested before breakfast, as only $5 \%$ of proton pumps are in their active state at fasting, but after breakfast, about $60 \sim 70 \%$ of proton pumps are active. ${ }^{12}$ Furthermore, taking a PPI with a meal may decrease systemic bioavailability and delay peak plasma concentrations. ${ }^{13}$ Amoxicillin and clarithromycin are usually taken after a meal in order to reduce adverse effects of the drugs, such as epigastric soreness or gastrointestinal trouble. However, asking H. pylori patients to

Copyright $\odot 2018$ Korean College of Helicobacter and Upper Gastrointestinal Research

(a) The Korean Journal of Helicobacter and Upper Gastrointestinal Research is an Open-Access Journal. All articles are distributed under the terms of the Creative Commons Attribution Non-Commercial License (http://creativecommons.org/licenses/by-nc/4.0) which permits unrestricted non-commercial use, distribution, and reproduction in any medium, provided the original work is properly cited. 
take a PPI before a meal and the other two antibiotics after a meal could be ineffective considering the inconvenience and probable non-compliance of patients. The inconvenience and the decreased patient compliance could lead to a reduced effectiveness of the triple therapy. To date, no study has measured the effects of taking the triple therapy of drugs all at once after a meal, or dividing them, taking PPIs before a meal and antibiotics after a meal.

In this study, we aimed to compare the eradication rate of $H$. pylori in a single medical center using two methods in practice: three drugs at once after a meal or a PPI before a meal and antibiotics after a meal. We then tried to determine the effectiveness of prescribing PPIs before a meal separately for treatment of $H$. pylori.

\section{MATERIALS AND METHODS}

\section{Patients and data collection}

This study was a retrospective, single center study. We reviewed the medical records of patients who visited Kosin Unversity Gospel Hospital for treatment of H. pylori, between January 2008 and December 2012. A total of 276 patients who had tested positive for rapid urease were treated for $H$. pylori with standard triple therapy at Kosin Unversity Gospel Hospital. Of these patients, 80 patients took a PPI 30 minutes before a meal and antibiotics after meal, while the other 196 patients took all three drugs at once after a meal. To reduce the effect of confounders in the two groups based on the administration method, we randomly matched the patients according to sex and age at a 1:1 ratio by using a random table. We divided the two groups according to the administration method used for triple therapy for eradication of H. pylori. Group A included the patients who took a PPI before a meal and two antibiotics after a meal; group B included the patients who took the three drugs at once after a meal. This study was approved by the Institutional Review Board of Kosin University Gospel Hospital (IRB no. KUGH 2013-063).

\section{Medication}

The regimen included lansoprazole $(30 \mathrm{mg}$ ), amoxicillin
(1,000 mg), and clarithromycin (500 mg). All drugs were taken twice a day for seven days. There was no pharmaceutical company participation. All patients were asked to avoid smoking, alcohol, foods rich in tyramine and seafood, from the start of treatment until one week after.

\section{Adverse effects}

A follow-up appointment was scheduled with patients four weeks after triple therapy, where patients were tested for any adverse effects.

\section{Main outcome measures}

At least four weeks after the end of treatment a ${ }^{13} \mathrm{C}$-urea breath test $\left({ }^{13} \mathrm{C}\right.$-UBT) was performed to validate eradication of $H$. pylori. All patients took tables including $100 \mathrm{mg}$ of ${ }^{13} \mathrm{C}$-urea (UBiTkit ${ }^{\mathrm{TM}}$; Otsuka Pharmaceutical, Tokyo, Japan) with $100 \mathrm{~mL}$ of water orally, and the second breath sample was obtained 20 minutes after taking the tablets. The ${ }^{13} \mathrm{C}-\mathrm{UBT}$ (UBiT-IR300 ${ }^{\circledR}$; Otsuka Electronics, Osaka, Japan) was considered negative if the delta value was below four.

\section{Statistical analysis}

IBM SPSS Statistics for Windows ver. 20.0 (IBM Co., Armonk, NY, USA) was used to perform the statistical analysis. The chi-square test was used to analyze categorical variables and the Student's t-test was used to analyze quantitative variables. All results were considered statistically significant when $P$ values were $<0.05$.

\section{RESULTS}

One hundred sixty patients were included in this study. Of the 160 patients, 80 were included in group A and 80 were included in group B. The baseline characteristics of the patients and causes of $H$. pylori eradication are summarized in Table 1.

The eradication rate of group A was 72.5\% (58/80) and the eradication rate of group B was $75.0 \%(60 / 80)$. There was no significant difference between the two groups $(P=0.719)$ (Table 2). Few patients in either group experienced any adverse effects (Table 2): 4 of 80 patients (5.0\%) in group A and 7 of 80 patients (8.8\%) in group B. 
Table 1. Baseline Characteristics of Patients and Causes of Helicobacter pylori Eradication

\begin{tabular}{lccc}
\hline \multicolumn{1}{c}{ Variable } & Group A & Group B & $P$ value \\
\hline Number of patients & 80 & 80 & \\
Age (yr) & $53.3 \pm 12.5$ & $51.5 \pm 12.2$ & 0.334 \\
Sex (male/female) & $59 / 21$ & $50 / 30$ & 0.127 \\
Causes of $H$. pylori eradication & & & 0.015 \\
Gastric ulcer, scar & 23 & 18 & \\
Gastric ulcer, active & 1 & 0 & \\
Duodenal ulcer, scar & 25 & 44 & \\
Duodenal ulcer, active & 5 & 1 & \\
MALT lymphoma & 0 & 2 & \\
Post EMR & & \\
Lymphofollicular gastritis & 12 & 5 & \\
Wanted by patients & 4 & 6 & \\
\hline
\end{tabular}

Values are presented as number only or mean \pm standard deviation. Group A, the patients who took a proton pump inhibitor before a meal and two antibiotics after a meal; Group B, the patients who took the three drugs at once after a meal; MALT, mucosa-associated lymphoid tissue; EMR, endoscopic mucosal resection.

${ }^{a}$ Patients who had received endoscopic treatment for adenoma or early gastric cancer.

All adverse effects were self-limiting, so the patients who experienced adverse effects did not quit the drugs. There was also no significant difference in adverse effects experienced by groups ( $P=0.232$ ) (Table 2 ).

\section{DISCUSSION}

In this study, we aimed to compare the eradication rate of $H$. pylori between two administration methods of triple therapy. Worldwide, the eradication rate of $H . p y^{-}$ lori has recently gradually decreased, and in South Korea, the eradication rate of first-line treatment has also gradually decreased. According to a systemic review reported in South Korea, the eradication rate was 90\% in 1997 1998 , but that rate has decreased continuously to less than $80 \%$ in 2009 , and $75.8 \%$ in $2012 .{ }^{14}$ The eradication rate in our study was similar to the result in 2012 $(73.8 \%)$. There are many factors that contribute to a decrease in the eradication rate of $H$. pylori, the most common cause is the increase in resistance to clarithromycin, and the compliance of patients is thought to be also important cause. Therefore, new therapeutic strategies against $H$. pylori infection that have been tried all over the world include sequential therapy, ${ }^{15-19}$ concomitant
Table 2. Eradication Rate of Helicobacter pylori and Adverse Effects after Triple Therapy in Group A and B $(n=80)$

\begin{tabular}{lccc}
\hline \multicolumn{1}{c}{ Variable } & Group A & Group B & $P$ value \\
\hline Eradication rate of H. pylori & $58(72.5)$ & $60(75.0)$ & 0.719 \\
Adverse effects & & & \\
No symptom & 76 & 73 & \\
Epigastric discomfort & 1 & 2 & \\
Diarrhea & 3 & 3 & \\
Constipation & 0 & $2^{\mathrm{a}}$ & \\
Nausea/vomiting & 0 & $1^{\mathrm{a}}$ & \\
Dizziness & 0 & $1^{\mathrm{a}}$ & \\
\hline
\end{tabular}

Values are presented as number (\%) or number only.

Group A, the patients who took a proton pump inhibitor before a meal and two antibiotics after a meal; Group B, the patients who took the three drugs at once after a meal.

${ }^{a}$ Accompanied symptoms for one patient.

therapy, ${ }^{20-22}$ and tailored therapy. ${ }^{23,24}$ Compliance with therapy is also important factor in $H$. pylori eradication. Poor compliance with therapy could be contribute to lower levels of eradication. ${ }^{25}$ We hypothesized that poor compliance with $H$. pylori eradication might associated with inconvenient taking drugs. Therefore, we divided into two groups and compared the eradication rate of $H$. Pylori between two administration methods of triple therapy.

The dividing method, which prescribes taking a PPI before a meal and antibiotics after a meal, has a high probability of patient incompliance due to inconvenience. However, no reports have shown a difference in eradication rates between the dividing method and the all-at-once method of triple therapy. In this study, we compared the eradication rate of two groups. H. pylori was successfully eradicated in group A and group B, in 58 of 80 patients (72.5\%) and in 60 of 80 patients $(75.0 \%$, respectively. There was no significant difference in eradication rates between the two groups $(P=0.719)$. There was also no significant difference in the prevalence of adverse effects between the two groups $(P=0.232)$. According to these results, the method that prescribes taking a PPI before a meal and two antibiotics after a meal is no more effective than prescribing all three drugs at once after a meal.

PPI is known to be most effective when taken before breakfast, and amoxicillin and clarithromycin are usually taken after a meal to reduce the adverse effects of the 
drugs, such as epigastric soreness or gastrointestinal trouble. Hatlebakk et al. ${ }^{26}$ reported that during the 9-hour daytime period, median gastric $\mathrm{pH}$ increases by 0.9 and the percentage of time for which gastric $\mathrm{pH}<4$ was more than halved when PPI was taken before breakfast compared with no breakfast. Thus, it was suggested that a morning dose of PPI should be taken before a meal for optimal efficacy. Amoxycillin is most stable over the $\mathrm{pH}$ range $4.0 \sim 7.0$, and the optimum stability of clarithromycin was observed to be in the $\mathrm{pH}$ range 5.0 8.0. Because both antibiotics degrade markedly at $\mathrm{pH}$ values below 5.0, a gastric pH greater than 5.0 should be maintained for effective eradication of $H$. pylori. ${ }^{7}$ Although further studies are needed, we think that taking all three drugs after meals could also increase the gastric acid $\mathrm{pH}$ to above 5.0.

There were some limitations in this study. First, this study was retrospectively performed. Therefore, we are not sure that the patients included in this study took drugs accurately, based on their prescription. However, we repeatedly emphasized the administration method of the drugs to our patients in the outpatient clinic, and the patients listened to an explanation of the administration method again in the pharmacy. We believe that the possibility of taking the drugs incorrectly was minimized by these efforts. Second, the adverse events of patients in this study are too low compared to previous studies, ${ }^{27}$ and these results might be caused by limitations of retrospective studies. However, we tried to minimize any bias by repeatedly reviewing the medical records. Third, the number of patients included in this study was low, and then it might be insufficient to draw a conclusion from our data. And a selection bias may have occurred in the process of choosing the patients for group B through age-sexed matched control. To resolve these problems, further studies including large number of patients are needed.

This study is the first to compare the difference in eradication rates according to the administration method of the three drugs used for triple therapy (whether taken all at once after a meal or divided into a PPI before a meal and antibiotics after a meal). There was no significant difference in eradication rate between these two administration methods. Although further studies are needed to confirm this result, the prescription of three drugs as triple therapy to be taken at once after a meal may be better way than the dividing method, considering the convenience and likelihood of compliance of patients.

\section{REFERENCES}

1. Marshall BJ, Warren JR. Unidentified curved bacilli in the stomach of patients with gastritis and peptic ulceration. Lancet 1984;1:1311-1315.

2. Suerbaum S, Michetti P. Helicobacter pylori infection. N Engl J Med 2002;347:1175-1186.

3. Ito M, Takata S, Tatsugami M, et al. Clinical prevention of gastric cancer by Helicobacter pylori eradication therapy: a systematic review. J Gastroenterol 2009;44:365-371.

4. Kodama M, Murakami K, Okimoto T, et al. Helicobacter pylori eradication improves gastric atrophy and intestinal metaplasia in long-term observation. Digestion 2012;85:126-130.

5. Kodama M, Murakami K, Okimoto T, et al. Ten-year prospective follow-up of histological changes at five points on the gastric mucosa as recommended by the updated Sydney system after Helicobacter pylori eradication. J Gastroenterol 2012;47:394403.

6. Gisbert JP, Calvet X. Review article: the effectiveness of standard triple therapy for Helicobacter pylori has not changed over the last decade, but it is not good enough. Aliment Pharmacol Ther 2011;34:1255-1268.

7. Erah PO, Goddard AF, Barrett DA, Shaw PN, Spiller RC. The stability of amoxycillin, clarithromycin and metronidazole in gastric juice: relevance to the treatment of Helicobacter pylori infection. J Antimicrob Chemother 1997;39:5-12.

8. Bayerdörffer E, Miehlke S, Mannes GA, et al. Double-blind trial of omeprazole and amoxicillin to cure Helicobacter pylori infection in patients with duodenal ulcers. Gastroenterology 1995;108:1412-1417.

9. Labenz J, Stolte M, Blum AL, et al. Intragastric acidity as a predictor of the success of Helicobacter pylori eradication: a study in peptic ulcer patients with omeprazole and amoxicillin. Gut 1995;37:39-43.

10. Fan HY, Wang J, Yan GC, et al. Increasing gastric juice pH level prior to anti-Helicobacter pylori therapy may be beneficial to the healing of duodenal ulcers. Exp Ther Med 2013;5:912-916.

11. Grayson ML, Eliopoulos GM, Ferraro MJ, Moellering RC Jr. Effect of varying pH on the susceptibility of Campylobacter pylori to antimicrobial agents. Eur J Clin Microbiol Infect Dis 1989;8: 888-889.

12. Scarpignato C, Pelosini I, Di Mario F. Acid suppression therapy: where do we go from here? Dig Dis 2006;24:11-46.

13. Bergstrand R, Grind M, Nyberg G, Olofsson B. Decreased oral bioavailability of lansoprazole in healthy volunteers when given with a standardised breakfast. Clin Drug Investig 1995;9:67-71. 
14. Heo J, Jeon SW. Changes in the eradication rate of conventional triple therapy for Helicobacter pylori infection in Korea. Korean J Gastroenterol 2014;63:141-145.

15. Gatta L, Vakil N, Leandro G, Di Mario F, Vaira D. Sequential therapy or triple therapy for Helicobacter pylori infection: systematic review and meta-analysis of randomized controlled trials in adults and children. Am J Gastroenterol 2009;104:3069-3079; quiz 1080.

16. Jafri NS, Hornung CA, Howden CW. Meta-analysis: sequential therapy appears superior to standard therapy for Helicobacter pylori infection in patients naive to treatment. Ann Intern Med 2008;148:923-931.

17. Kim JS, Kim BW, Ham JH, et al. Sequential therapy for Helicobacter pylori infection in Korea: systematic review and meta-analysis. Gut Liver 2013;7:546-551.

18. Tong JL, Ran ZH, Shen J, Xiao SD. Sequential therapy vs. standard triple therapies for Helicobacter pylori infection: a meta-analysis. J Clin Pharm Ther 2009;34:41-53.

19. Zullo A, Rinaldi V, Winn S, et al. A new highly effective short-term therapy schedule for Helicobacter pylori eradication. Aliment Pharmacol Ther 2000;14:715-718.

20. Essa AS, Kramer JR, Graham DY, Treiber G. Meta-analysis: four-drug, three-antibiotic, non-bismuth-containing "concomitant therapy" versus triple therapy for Helicobacter pylori eradication. Helicobacter 2009;14:109-118.

21. Fischbach LA, van Zanten S, Dickason J. Meta-analysis: the effi- cacy, adverse events, and adherence related to first-line anti-Helicobacter pylori quadruple therapies. Aliment Pharmacol Ther 2004;20:1071-1082.

22. Gisbert JP, Calvet X. Review article: non-bismuth quadruple (concomitant) therapy for eradication of Helicobater pylori. Aliment Pharmacol Ther 2011;34:604-617.

23. Furuta T, Shirai N, Kodaira M, et al. Pharmacogenomics-based tailored versus standard therapeutic regimen for eradication of H. pylori. Clin Pharmacol Ther 2007;81:521-528.

24. Lee HJ, Kim JI, Cheung DY, et al. Eradication of Helicobacter pylori according to 23S ribosomal RNA point mutations associated with clarithromycin resistance. J Infect Dis 2013;208: 1123-1130.

25. O'Connor JP, Taneike I, O'Morain C. Improving compliance with Helicobacter pylori eradication therapy: when and how? Therap Adv Gastroenterol 2009;2:273-279.

26. Hatlebakk JG, Katz PO, Camacho-Lobato L, Castell DO. Proton pump inhibitors: better acid suppression when taken before a meal than without a meal. Aliment Pharmacol Ther 2000; 14:1267-1272.

27. Luther J, Higgins PD, Schoenfeld PS, Moayyedi P, Vakil N, Chey WD. Empiric quadruple vs. triple therapy for primary treatment of Helicobacter pylori infection: systematic review and meta-analysis of efficacy and tolerability. Am J Gastroenterol 2010;105:65-73. 